\title{
Attentional Capture in the Chimpanzee (Pan Rroglodites): Distractor of a Singleton on Visual Search Performances
}

\section{Tomonaga}

\section{OpenEdition}

\section{Journals}

Electronic version

URL: http://journals.openedition.org/cpl/209

DOI: $10.4000 / \mathrm{cpl} .209$

ISSN: $1379-6100$

\section{Publisher}

Centre PsyCLÉ

\section{Printed version}

Date of publication: 1 August 2002

\section{Electronic reference}

M. Tomonaga, «Attentional Capture in the Chimpanzee (Pan Rroglodites): Distractor of a Singleton on Visual Search Performances », Current psychology letters [Online], 2002/2, 8| 2002, Online since 05 September 2003, connection on 08 September 2020. URL : http://journals.openedition.org/cpl/209 ; DOI : https://doi.org/10.4000/cpl.209

This text was automatically generated on 8 September 2020 .

(c) All rights reserved 


\section{Attentional Capture in the Chimpanzee (Pan Rroglodites): Distractor of a Singleton on Visual Search Performances}

M. Tomonaga 